\title{
Differential effects of iodoacetamide and iodoacetate on glycolysis and glutathione metabolism of cultured astrocytes
}

\author{
Maike M. Schmidt ${ }^{1,2}$ and Ralf Dringen ${ }^{1,2,3 *}$ \\ 1 Center for Biomolecular Interactions Bremen, University of Bremen, Bremen, Germany \\ 2 Center for Environmental Research and Sustainable Technology, University of Bremen, Bremen, Germany \\ ${ }^{3}$ School of Psychology, Psychiatry, and Psychological Medicine, Monash University, Clayton, Australia
}

\section{Edited by:}

Luc Pellerin, University of Lausanne,

Switzerland

Reviewed by:

Carole Escartin, CEA, France

Suzie Lavoie, CHUV-UNIL, Lausanne

*Correspondence:

Ralf Dringen, Center for Biomolecular Interactions Bremen, University of

Bremen, P.O. Box 330440, D-28334

Bremen, Germany.

e-mail: ralf.dringen@uni-bremen.de lodoacetamide (IAA) and iodoacetate (IA) have frequently been used to inhibit glycolysis, since these compounds are known for their ability to irreversibly inhibit the glycolytic enzyme glyceraldehyde-3-phosphate dehydrogenase (GAPDH). However, the consequences of a treatment with such thiol reagents on the glutathione (GSH) metabolism of brain cells have not been explored. Exposure of astroglia-rich primary cultures to IAA or IA in concentrations of up to $1 \mathrm{mM}$ deprived the cells of GSH, inhibited cellular GAPDH activity, lowered cellular lactate production and caused a delayed cell death that was detectable after 90 min of incubation. However, the two thiol reagents differed substantially in their potential to deprive cellular GSH and to inhibit astrocytic glycolysis. IAA depleted the cellular GSH content more efficiently than IA as demonstrated by half-maximal effects for IAA and IA that were observed at concentrations of about 10 and $100 \mu \mathrm{M}$, respectively. In contrast, IA was highly efficient in inactivating GAPDH and lactate production with half-maximal effects observed already at a concentration below $100 \mu \mathrm{M}$, whereas IAA had to be applied in 10 times higher concentration to inhibit lactate production by $50 \%$. These substantial differences of IAA and IA to affect GSH content and glycolysis of cultured astrocytes suggest that in order to inhibit astrocytic glycolysis without substantially compromising the cellular GSH metabolism, IA - and not IAA - should be used in low concentrations and/or for short incubation periods.

Keywords: alkylation, astrocytes, carboxymethylation, GAPDH, glycolysis, GSH, lactate, thiol reagents

\section{INTRODUCTION}

The thiol reagents iodoacetamide (IAA) and iodoacetate (IA) (Figure 1) are frequently used as alkylating reagents to modify thiol groups in proteins by S-carboxyamidomethylation and S-carboxymethylation, respectively. IAA and IA have been used to study the importance of cysteine residues in catalytic reactions of enzymes and in transport processes of brain cells (Albrecht et al., 1993; Aschner et al., 1994; Gali and Board, 1997) and to derivatise cysteine residues in proteins for proteomic approaches (Adachi et al., 2005; Sun et al., 2008; Williams et al., 2008). The inactivation of glyceraldehyde-3-phosphate dehydrogenase (GAPDH) by IAA and IA (Sabri and Ochs, 1971; Williamson, 1967) is often used as text book example for an irreversible enzyme inhibition. The essential cysteine residue in the active center of GAPDH forms a thioether bond with IAA or IA and can therefore not react anymore with the physiological substrate glyceraldehyde-3-phosphate. As a consequence, GAPDH is inactivated after exposure to IAA or IA and glycolysis is inhibited.

On cultured astrocytes and glial cell lines, IAA and IA have been used to inhibit glycolysis (Bakken et al., 1998; Bickler and Kelleher, 1992; Gemba et al., 1994; Loreck et al., 1987; Ogata et al., 1995) and to study the consequences of ATP depletion and hypoglycemia (Kauppinen et al., 1988; Nodin et al., 2005; Parkinson et al., 2002; Sun et al., 1993; Taylor et al., 1996). However, during treatment of cells or tissue with IAA or IA, side effects that are caused by the unspecific reaction of IAA and IA as thiol reagents cannot be excluded. In this context, especially the reactions of IAA and IA with low molecular weight cellular thiols such as GSH (Chen and Stevens, 1991; Liu et al., 1996) have to be considered.

The tripeptide GSH ( $\gamma$-L-glutamyl-L-cysteinylglycine) is a cellular thiol that is present in millimolar concentrations in mammalian cells (Cooper and Kristal, 1997). GSH has many important functions in cells. Among those, the antioxidative and detoxifying functions of GSH are most likely the most important ones for many cell types and tissues. GSH serves as electron donor for the reduction of peroxides by glutathione peroxidases (Margis et al., 2008) and is substrate for the detoxification of xenobiotics in the reactions that are catalyzed by glutathione- $S$-transferases (Hayes et al., 2005).

In the brain, astrocytes play a very important role in the antioxidative defense and in the detoxification of xenobiotics (Aoyama et al., 2008; Ballatori et al., 2008; Cooper and Kristal, 1997; Dringen, $2000,2009)$. Cultured astrocytes contain GSH in a cytosolic concentration of $8 \mathrm{mM}$ (Dringen and Hamprecht, 1998). These cells rely on a high GSH concentration for the rapid clearance of peroxides (Dringen et al., 2005; Liddell et al., 2006a,b) for the resistance against oxidative stress (Bi et al., 2008; Bishop et al., 2007; Gegg et al., 2003, 2005; Giordano et al., 2008) and for the GSH-dependent detoxification of xenobiotics (Kubatova et al., 2006; Sagara and Sugita, 2001; Waak and Dringen, 2006).

Although IAA and IA have often been used to modulate the glucose metabolism of cultured astrocytes, the consequences of a 


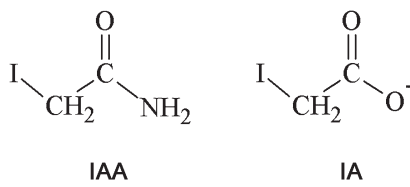

FIGURE 1 | Structural formulas of iodoacetamide (IAA) and iodoacetate (IA). and incubated in the cell incubator with $0.5 \mathrm{~mL} \mathrm{IB}$ containing IAA or IA in the concentrations given in the figures. For analysis of the total cellular glutathione content $(\mathrm{GSx}=$ amount of $\mathrm{GSH}$ plus twice the amount of GSSG), the cells were washed with $1 \mathrm{~mL}$ phosphatebuffered saline (PBS; $10 \mathrm{mM}$ potassium phosphate buffer, $150 \mathrm{mM}$ $\mathrm{NaCl}, \mathrm{pH}$ 7.4) and lysed with $0.5 \mathrm{~mL} 1 \%$ (w/v) sulfosalicylic acid. Ten microliters of aliquote parts of the lysates were used to quantify the cellular GSx content.

\section{CHEMICAL REACTION OF GSH WITH IAA OR IA}

GSH $(10 \mu \mathrm{M})$ was incubated with the indicated concentrations of IAA or IA in a total volume of $1 \mathrm{~mL}$ at room temperature in IB for up to $60 \mathrm{~min}$. At the time points indicated, $10 \mu \mathrm{L}$ sample of the reaction mixture were mixed with $10 \mu \mathrm{L} 1 \%$ sulfosalicylic acid before the GSx content was determined as described below.

\section{DETERMINATION OF GLUTATHIONE}

The contents of GSx and GSSG in cell lysates and incubation media were determined as described previously (Dringen and Hamprecht, 1996; Dringen et al., 1997) in microtiter plates according to the colorimetric method originally described by Tietze (Tietze, 1969). The detection limit of this assay was about $0.2 \mathrm{nmol}$ GSx per $500 \mu \mathrm{L}$ lysate or medium.

\section{MATERIALS AND METHODS MATERIALS}

IAA, IA and 5,5'-dithio-bis(2-nitrobenzoic acid) were obtained from Sigma-Aldrich (Steinheim, Germany). Glucose-6-phosphate, glutamate pyruvate transaminase, GSH, glutathione disulfide (GSSG), glutathione reductase (GR), glyceraldehyde-3-phosphate, lactate dehydrogenase (LDH), maleimide and potassium arsenate were from Roche Diagnostics (Mannheim, Germany). Bovine serum albumin, $\mathrm{NAD}^{+}, \mathrm{NADH}, \mathrm{NADP}^{+}, \mathrm{NADPH}$ and sulfosalicylic acid were purchased from Applichem (Darmstadt, Germany). Fetal calf serum, streptomycin sulfate and penicillin $\mathrm{G}$ were from Biochrom (Berlin, Germany). Dulbecco's modified Eagle's medium (DMEM) was purchased from Invitrogen (Karlsruhe, Germany). All other chemicals were obtained from Fluka (Buchs, Switzerland) or Merck (Darmstadt, Germany) at analytical grade. Sterile cell culture material and unsterile 96-well plates were from Nunc (Roskilde, Denmark) and Sarstedt (Karlsruhe, Germany).

\section{CELL CULTURES}

Astroglia-rich primary cultures derived from the whole brains of neonatal Wistar rats were prepared as previously described (Hamprecht and Löffler, 1985). Three hundred thousand viable cells were seeded per well of a 24 -well dish in $1 \mathrm{~mL}$ culture medium ( $90 \%$ DMEM, $10 \%$ fetal calf serum, $20 \mathrm{U} / \mathrm{mL}$ of penicillin $\mathrm{G}$ and $20 \mu \mathrm{g} / \mathrm{mL}$ of streptomycin sulfate) and cultured in a cell incubator (Sanyo, Osaka, Japan) that contained a humidified atmosphere of $10 \% \mathrm{CO}_{2} / 90 \%$ air. The culture medium was renewed every seventh day. The results described here were obtained on 14- to 23-day-old cultures.

\section{EXPERIMENTAL INCUBATION OF CELLS}

To study the consequences of a treatment of astrocytes with IAA or IA, the cells were washed with $1 \mathrm{~mL}$ of prewarmed $\left(37^{\circ} \mathrm{C}\right)$ incubation buffer (IB; $1.8 \mathrm{mM} \mathrm{CaCl}_{2}, 1 \mathrm{mM} \mathrm{MgCl}_{2}, 5.4 \mathrm{mM} \mathrm{KCl}, 145 \mathrm{mM}$ $\mathrm{NaCl}, 0.8 \mathrm{mM} \mathrm{Na}_{2} \mathrm{HPO}_{4}, 20 \mathrm{mM}$ HEPES, 5 mM D-Glucose, pH 7.4)

\section{DETERMINATION OF LACTATE IN CULTURE MEDIUM}

Extracellular lactate concentration in culture media was determined using a modification of an established assay (Dringen et al., 1993). Briefly, $20 \mu \mathrm{L}$ media sample were diluted with $160 \mu \mathrm{L}$ purified water in wells of a microtiter plate and mixed with $180 \mu \mathrm{L}$ reaction mixture $\left(5.6 \mathrm{mM} \mathrm{NAD}^{+}, 19.9 \mathrm{U} / \mathrm{mL} \mathrm{LDH}, 1.94 \mathrm{U} / \mathrm{mL}\right.$ glutamate pyruvate transaminase in $250 \mathrm{mM}$ glutamate/ $\mathrm{NaOH}$ buffer, $\mathrm{pH}$ 8.9). After incubation for $90 \mathrm{~min}$ in a humidified atmosphere at $37^{\circ} \mathrm{C}$ the absorbance of the NADH generated from lactate was determined at $340 \mathrm{~nm}$ using a Sunrise microtiter plate photometer (Tecan, Austria). Media samples containing no lactate were used as blanks.

\section{DETERMINATION OF ENZYME ACTIVITIES}

The cells were washed with $1 \mathrm{~mL}$ ice-cold PBS and subsequently lysed by incubation with $200 \mu \mathrm{L} 20 \mathrm{mM}$ potassium phosphate buffer ( $\mathrm{pH}$ 7.0) for $10 \mathrm{~min}$ on ice. The lysates were scrapped of the wells and transferred into Eppendorf cups. After centrifugation (1 min, $12,000 \mathrm{~g}$, room temperature) $20 \mu \mathrm{L}$ volumes of the supernatant were used to determine enzyme activities in wells of microtiter plates at room temperature. GAPDH activity was determined using the method described by Bisswanger (2004). The reaction mixture contained in a total volume of $360 \mu \mathrm{L} 0.9 \mathrm{mM}$ glyceraldehyde-3phosphate, $3 \mathrm{mM}$ potassium dihydrogen arsenate, $2 \mathrm{mM} \mathrm{NAD}^{+}$ and $93 \mathrm{mM}$ triethylamine hydrochloride/ $\mathrm{NaOH}$ buffer, $\mathrm{pH}$ 7.6. The increase of absorbance at $340 \mathrm{~nm}$ due to the reduction of $\mathrm{NAD}^{+}$ to NADH was followed over 10 min time. Glucose-6-phosphate dehydrogenase (G6PDH) activity was determined according to Deutsch (1984). The reaction mixture contained in a total volume of $200 \mu \mathrm{L} 6.3 \mathrm{mM} \mathrm{MgCl}, 5 \mathrm{mM}$ maleimide, $3.3 \mathrm{mM}$ glucose- 6 phosphate, $0.4 \mathrm{mM} \mathrm{NADP}^{+}$and $75 \mathrm{mM}$ Tris/HCl buffer, $\mathrm{pH}$ 7.5. The increase of absorbance at $340 \mathrm{~nm}$ due to the reduction of $\mathrm{NADP}^{+}$to NADPH was followed over $5 \mathrm{~min}$. LDH activity was 
determined using the method described previously (Dringen et al., 1998). The reaction mixture contained in a total volume of $360 \mu \mathrm{L}$ $1.8 \mathrm{mM}$ pyruvate, $0.2 \mathrm{mM} \mathrm{NADH}$ and $80 \mathrm{mM}$ Tris/ $\mathrm{HCl}$ buffer containing $200 \mathrm{mM} \mathrm{NaCl}, \mathrm{pH}$ 7.2. The decrease of absorbance at $340 \mathrm{~nm}$ due to the oxidation of $\mathrm{NADH}$ to $\mathrm{NAD}^{+}$was followed over $5 \mathrm{~min}$. GR activity was determined using a method described previously (Gutterer et al., 1999). The reaction mixture contained in a total volume of $300 \mu \mathrm{L} 1 \mathrm{mM}$ GSSG, $0.2 \mathrm{mM} \mathrm{NADPH}$ and $1 \mathrm{mM}$ EDTA in $100 \mathrm{mM}$ potassium phosphate buffer, $\mathrm{pH}$ 7.0. The decrease of absorbance at $340 \mathrm{~nm}$ due to the oxidation of NADPH was followed over $5 \mathrm{~min}$.

\section{DETERMINATION OF CELL VIABILITY AND PROTEIN CONTENT}

Loss of cell viability was analyzed by comparing the activity of $\mathrm{LDH}$ in the incubation medium with that of the cells using the microtiter plate assay described previously (Dringen et al., 1998). The presence of IAA or IA in a concentration of $1 \mathrm{mM}$ did not affect LDH activity in lysates of cultured astrocytes (data not shown). The protein content per well of a 24 -well dish was quantified after solubilization of the cells in $200 \mu \mathrm{L}$ of $0.5 \mathrm{M} \mathrm{NaOH}$ according to the Lowry method (Lowry et al., 1951) using bovine serum albumin as a standard. Total protein content per well and cytosolic protein in the supernatants of cell lysates (cytosolic protein) were used to calculate specific GSx or GSSG contents and specific enzyme activities, respectively.

\section{PRESENTATION OF THE DATA}

If not stated otherwise, the data are presented as mean \pm SD of values obtained in experiments on three independently prepared cultures. In the figures the bars have been omitted if they were smaller than the symbols representing the mean values. Statistical analysis of the significance of differences between multiple sets of data were performed by ANOVA followed by Bonferroni post hoc test. If not stated otherwise, statistical analysis of the significance of differences between two sets of data was performed using the paired $t$-test. The data shown in Figure 2 for IAA and IA were obtained separately and were therefore analyzed for significance by the unpaired $t$-test. $p>0.05$ was considered as not significant.

\section{RESULTS}

\section{CHEMICAL REACTION OF IAA OR IA WITH GSH}

To test whether IAA and IA react chemically with GSH, IAA or IA were mixed with GSH and the amount of detectable GSx was determined during an incubation period of up to $60 \mathrm{~min}$. In the presence of IAA (Figure 2A) or IA (Figure 2B) the amount of detectable GSx was lowered in a time- and concentration-dependent manner. For all concentrations of IAA or IA applied, the amount of GSx determined after 60 min of incubation was significantly lower after treatment with IAA than after exposure to IA (Figure 2C). Halfmaximal effects on the GSx content after 60 min of incubation with IAA and IA were observed for concentrations of about 0.2 and $1 \mathrm{mM}$, respectively (Figure 2C), demonstrating that IAA was more potent to react with GSH than IA.

\section{INACTIVATION OF ASTROCYTIC GAPDH BY IAA OR IA}

IAA and IA are well known to inhibit GAPDH activity (Sabri and Ochs, 1971; Williamson, 1967). To test for the potential of these

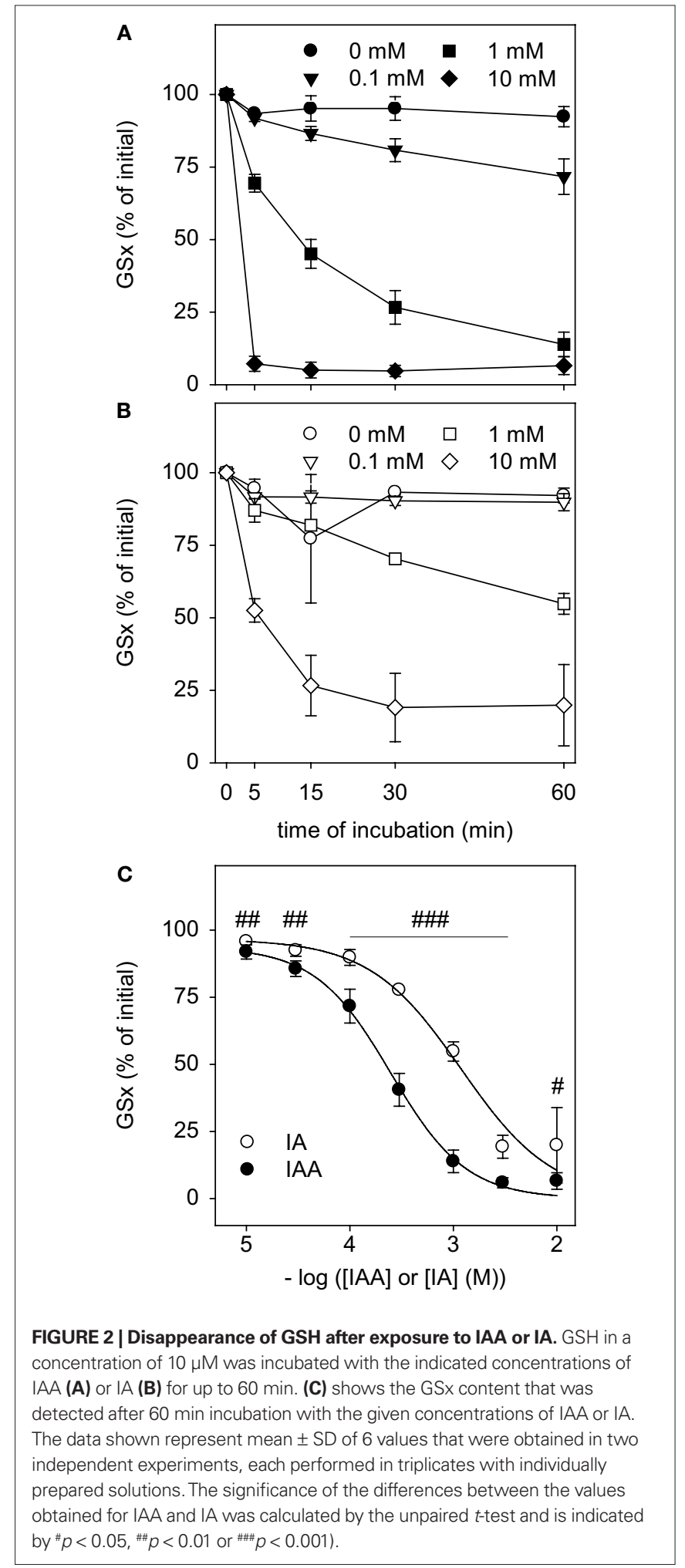

compounds to inactivate astrocytic GAPDH, cultured astrocytes were lysed and the GAPDH activity in the lysates was determined in the absence or presence of IAA or IA. In the absence of IAA and IA, the increase in absorbance that was caused by the GAPDHdependent formation of NADH was almost linear for up to $30 \mathrm{~min}$ 
(Figure 3). If the GAPDH reaction was monitored in the presence of IAA, the increase in NADH absorbance during the first 20 min of incubation was not significantly different $(p>0.05)$ from that of the

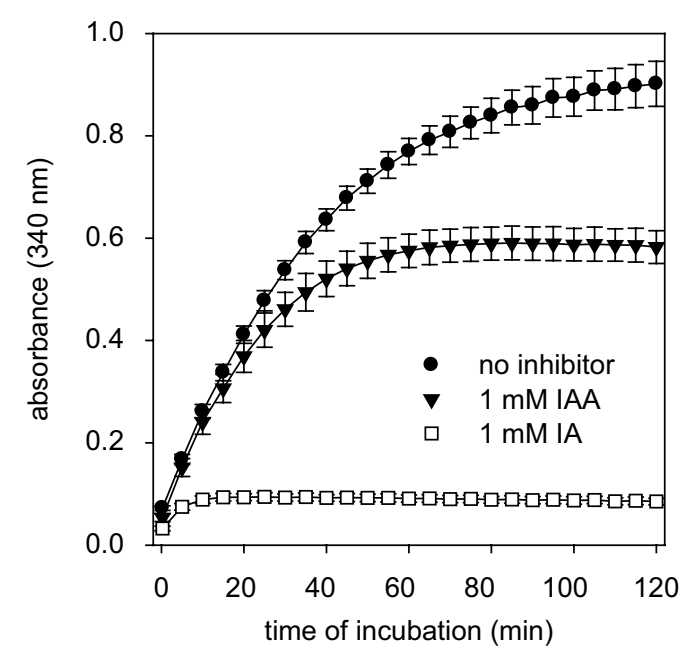

FIGURE 3 | GAPDH activity in cell lysates of astrocyte cultures in the absence or the presence of IAA or IA. The absorbance at $340 \mathrm{~nm}$ that indicates the formation of NADH by GAPDH was monitored. The results are presented as mean \pm SD of data that were obtained on cell lysates derived from three independently prepared cultures. control condition (absence of inhibitor) and it took about $60 \mathrm{~min}$ before the enzyme was completely inhibited (Figure 3). In contrast, in the presence of IA the increase in NADH absorbance was completely prevented within a few minutes (Figure 3).

\section{CONSEQUENCES OF A TREATMENT OF ASTROCYTE CULTURES WITH IAA OR IA}

To test for the consequences of a treatment of cultured astrocytes with IAA or IA, the cells were incubated with various concentrations of these compounds for up to $2 \mathrm{~h}$. After the indicated incubation times the extracellular activity of $\mathrm{LDH}$ as indicator for the loss of cell viability, the specific cellular GSx content as indicator for cellular GSH, and the lactate concentration in the medium as indicator for glycolytic activity were monitored.

During the first $60 \mathrm{~min}$ of incubation with IAA or IA, the cells remained viable as indicated by the lack of any increase $(p>0.05)$ in extracellular LDH activity compared to control (absence of IAA and IA) (Figures 4A,B). However, incubation of astrocytes with IAA or IA for longer than $60 \mathrm{~min}$ caused a significant increase in extracellular LDH activity that was moderate for $0.1 \mathrm{mM}$ IAA or IA but more severe for higher concentrations of both compounds (Figures 4A,B).

Exposure of cultured astrocytes to IAA caused a rapid decline of the cellular specific GSx content ( $p<0.001$ already after $5 \mathrm{~min}$ ) that resulted after 30 min incubation in cellular GSx levels below 20\% of control (absence of IAA) (Figure 4C). Also IA caused a decline

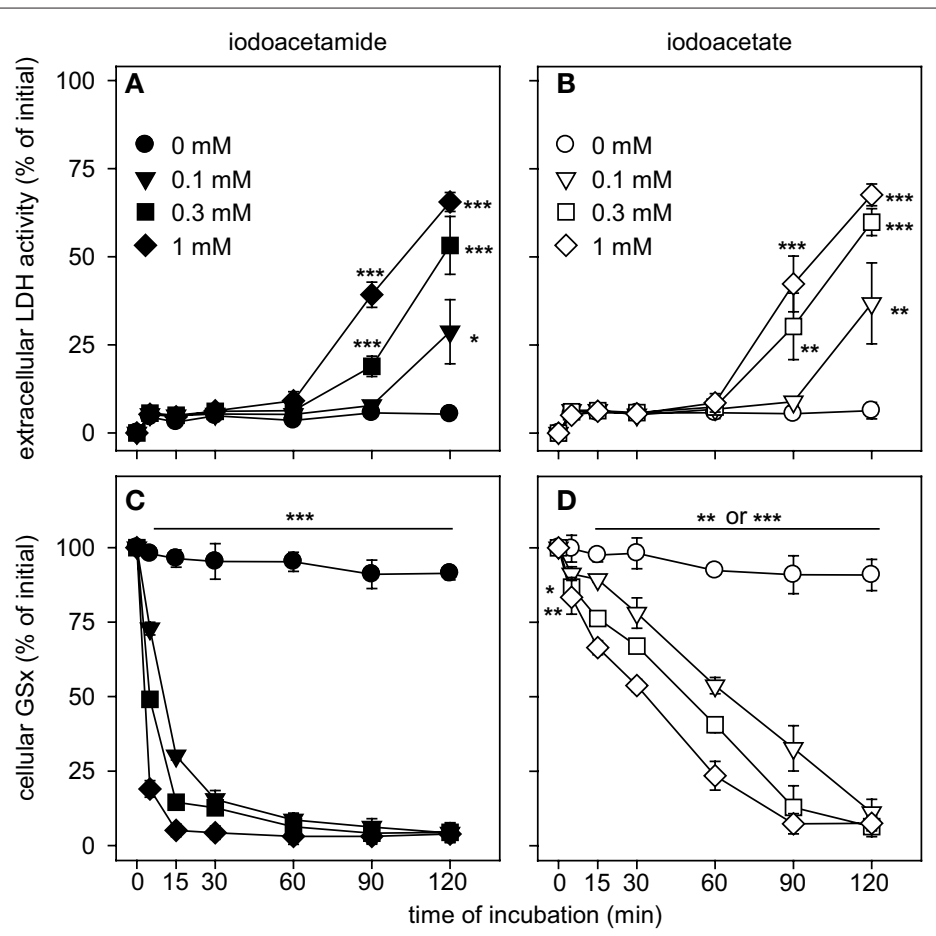

FIGURE 4 | Consequences of an application of IAA (A,C) or IA (B,D) on cellular viability $(A, B)$ and specific cellular $G S x$ content $(C, D)$ in astrocyte cultures. The cells were incubated for up to $120 \mathrm{~min}$ without or with IAA or IA in the concentrations indicated in (A) and (B). The results represent mean \pm SD of data that were obtained on three independently prepared cultures. The cultures contained initial protein contents of $80 \pm 8 \mu \mathrm{g}$ protein per well and initial specific GSx contents (100\%) of $46.2 \pm 10.2 \mathrm{nmol} / \mathrm{mg}$ protein. The significance of differences to the data obtained for the control condition (absence of inhibitor) are indicated by ${ }^{*} p<0.05,{ }^{*} p<0.01$ or ${ }^{* * *} p<0.001$. 
in cellular GSx content that depended on the concentration of IA applied (Figure 4D). However, this decline in cellular GSx after IA application (Figure 4D) was much slower than that observed for identical concentrations of IAA (Figure 4C) $(p<0.001$ after 5 min for all concentrations of IAA and IA applied). The concentrations causing half-maximal deprivation of cellular GSx after exposure of cultured astrocytes for $60 \mathrm{~min}$ to IAA and IA were about 10 and $100 \mu \mathrm{M}$, respectively, and differed by one order of magnitude (Figure 5).

The decline in cellular GSx that was observed after exposure of cultured astrocytes to IAA or IA (Figures 4C,D and 5) was not accompanied by an increase in cellular GSSG nor by an increase in the extracellular concentrations of GSx or GSSG (Table 1). In contrast, the extracellular contents of GSx and GSSG were lowered after incubation of the cells with IAA or IA (Table $\mathbf{1}$ ).

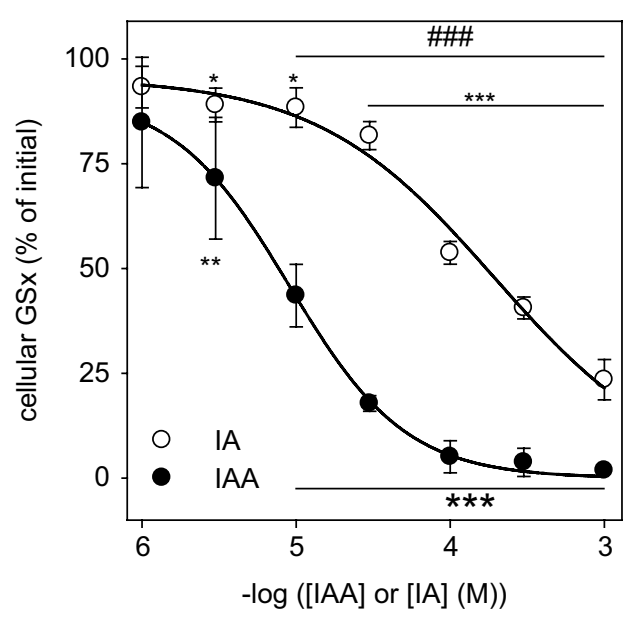

FIGURE 5 | Concentration dependency of the GSH depletion by IAA or IA in cultured astrocytes. The cells were incubated for $60 \mathrm{~min}$ with IAA or IA in concentrations of up to $1 \mathrm{mM}$. The results represent mean $\pm \mathrm{SD}$ of data that were obtained on three independently prepared cultures that contained $80 \pm 8 \mu \mathrm{g}$ protein per well. The initial specific GSx content (100\%) corresponded to $46.2 \pm 10.2 \mathrm{nmol} / \mathrm{mg}$ protein. The significance of differences to the data obtained for the control condition (absence of inhibitor) are indicated by ${ }^{*} p<0.05,{ }^{*} p<0.01$ or ${ }^{* *} p<0.001$. The significance of differences between the data observed after treatment with identical concentrations of IAA and IA was calculated by the paired $t$-test and is indicated by ${ }^{\# \#} p<0.001$.
Exposure of astrocytes to IAA hardly affected the extracellular accumulation of lactate during the first $60 \mathrm{~min}$ of incubation compared to control (Figure 6A), whereas a further increase of extracellular lactate was slowed during longer incubations, at least for IAA concentrations of 0.3 and $1 \mathrm{mM}$ (Figure 6A). The extracellular lactate concentration determined for cells that were treated with IAA for $60 \mathrm{~min}$ did not differ significantly to that of control cells (Figure 7A). In contrast, incubation of astrocytes with IA in a concentration of $1 \mathrm{mM}$ inhibited extracellular lactate accumulation much quicker than IAA (Figure 6B). In concentrations of 0.1 or $0.3 \mathrm{mM}$ IA almost completely prevented extracellular lactate accumulation within $30 \mathrm{~min}$ of incubation (Figure 6B). After 60 min of incubation the extracellular lactate concentrations of astrocyte cultures that were treated with $0.1,0.3$ and $1 \mathrm{mM}$ IA were significantly lowered to $40 \pm 7,24 \pm 16$ and $6 \pm 8 \%$, respectively, of the concentration determined for cells that were incubated without inhibitor (Figure 7A).

To demonstrate that indeed the inhibition of GAPDH by IAA or IA was responsible for the observed decline in the rate of glycolytic lactate production in astrocyte cultures, the specific activity of GAPDH was determined for cells that were treated for $60 \mathrm{~min}$ with various concentrations of IAA or IA. When the cells were exposed to 0.1 mM IAA the specific GAPDH activity was significantly lowered to half of that of controls (Figure 7B). In contrast, already after treatment of the cells with $0.1 \mathrm{mM}$ IA for $60 \mathrm{~min}$ GAPDH activity was not detectable anymore (Figure 7B). In concentrations of 0.3 and $1 \mathrm{mM}$, both IAA and IA completely inhibited GAPDH activity of astrocyte cultures within $60 \mathrm{~min}$ of incubation (Figure 7B).

To analyze how quickly the cellular GAPDH activity of cultured astrocytes was inactivated after exposure to IAA or IA, the cells were incubated with various concentrations of IAA or IA for time periods in the minute range (Figure 8). Half-maximal inhibition of astrocytic GAPDH by IAA that was applied in concentrations of $0.1,0.3$ and $1 \mathrm{mM}$ was observed after about 60,30 and $5 \mathrm{~min}$ of incubation, respectively (Figure 8A). In contrast, inactivation of GAPDH by the presence of IA was much faster that that by IAA. GAPDH activity was not detectable anymore after exposure of the cells for 5, 15 and 30 min to IA in concentrations of $1,0.3$ and $0.1 \mathrm{mM}$, respectively (Figure 8B).

To test whether IAA or IA are also able to inactivate other metabolic enzymes in cultured astrocytes, the cells were exposed for $60 \mathrm{~min}$ to IAA or IA in concentrations of $1 \mathrm{mM}$. Although these

Table 1 | Cellular and extracellular GSx and GSSG contents and extracellular LDH activity of primary astrocyte cultures after exposure to IAA or IA.

\begin{tabular}{|c|c|c|c|c|}
\hline & Control & IAA & IA & $n$ \\
\hline Cellular GSx (nmol/mg) & $41.9 \pm 7.6$ & $3.1 \pm 3.6^{* * *}$ & $8.9 \pm 5.6^{* * *}$ & 4 \\
\hline Cellular GSSG (nmol/mg) & $5.1 \pm 0.6$ & $2.0 \pm 2.0$ & $2.9 \pm 1.1$ & 3 \\
\hline Extracellular GSx (nmol/mg) & $4.7 \pm 0.5$ & $1.4 \pm 1.1^{*}$ & $2.4 \pm 1.4$ & 3 \\
\hline Extracellular GSSG (nmol/mg) & $3.8 \pm 0.5$ & $1.6 \pm 0.9 *$ & $2.6 \pm 0.9$ & 3 \\
\hline Extracellular LDH (\%) & $6.4 \pm 1.8$ & $12.2 \pm 6.5$ & $8.9 \pm 2.2$ & 4 \\
\hline
\end{tabular}

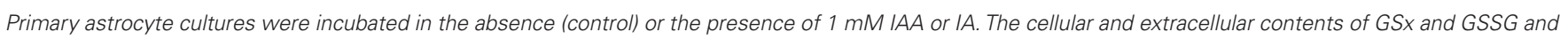

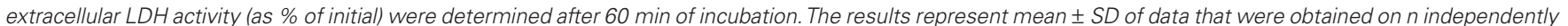

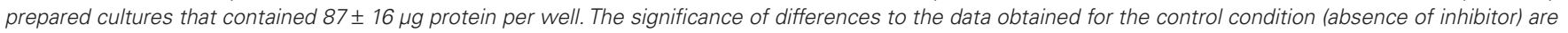
indicated by ${ }^{*} p<0.05$ or ${ }^{* * *} p<0.001$. 


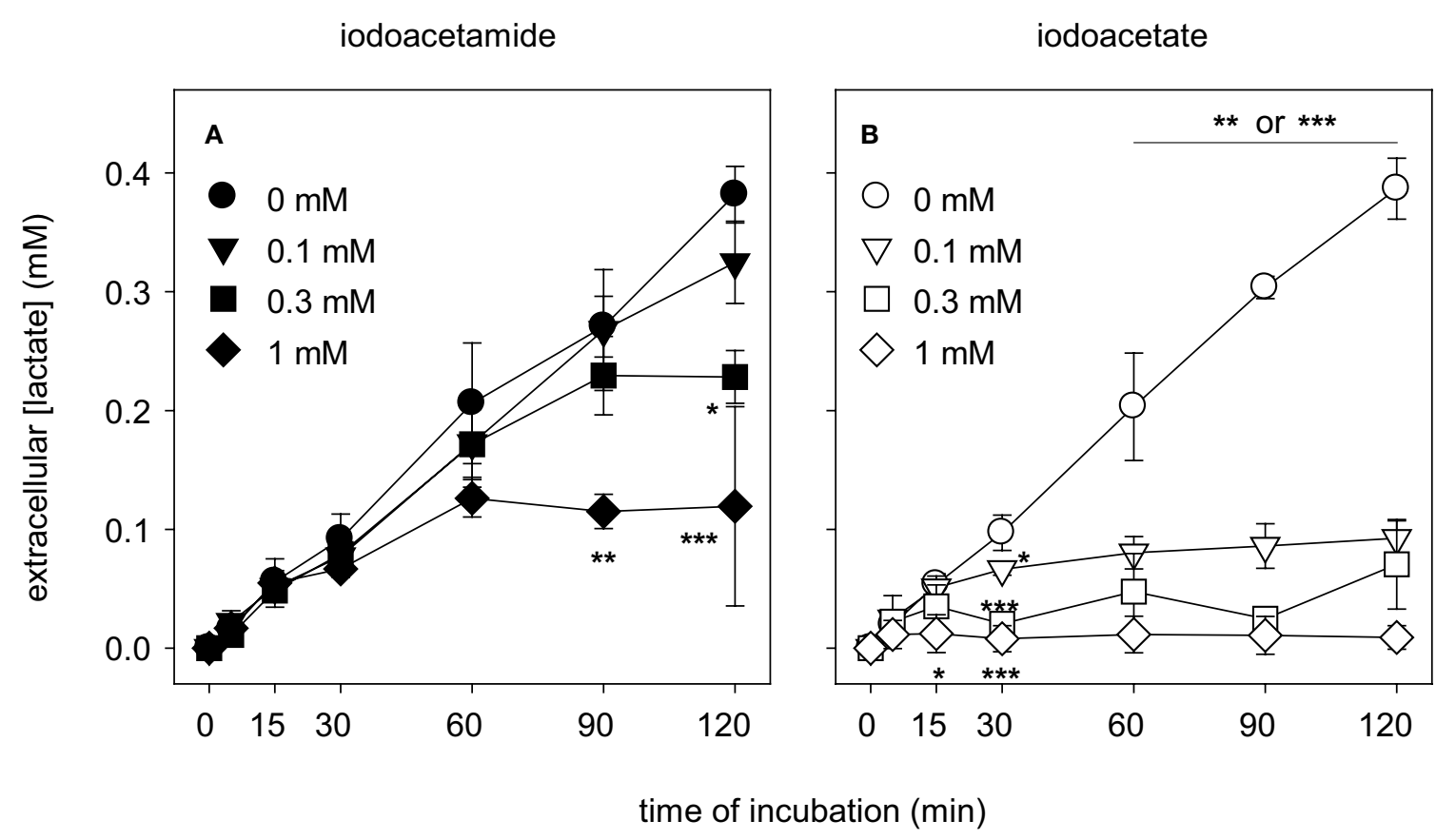

FIGURE 6 | Consequences of an application of IAA (A) or IA (B) on the extracellular lactate concentration in astrocyte cultures. The cells were incubated for up to 120 min without or with IAA or IA in the concentrations indicated in (A) and (B). The results represent mean \pm SD of data that were obtained on three independently prepared cultures. The cultures contained initial protein contents of $80 \pm 8 \mu \mathrm{g}$ protein per well. The significance of differences to the data obtained for the control condition (absence of inhibitor) are indicated by ${ }^{*} p<0.05,{ }^{* *} p<0.01$ or ${ }^{* * *} p<0.001$.

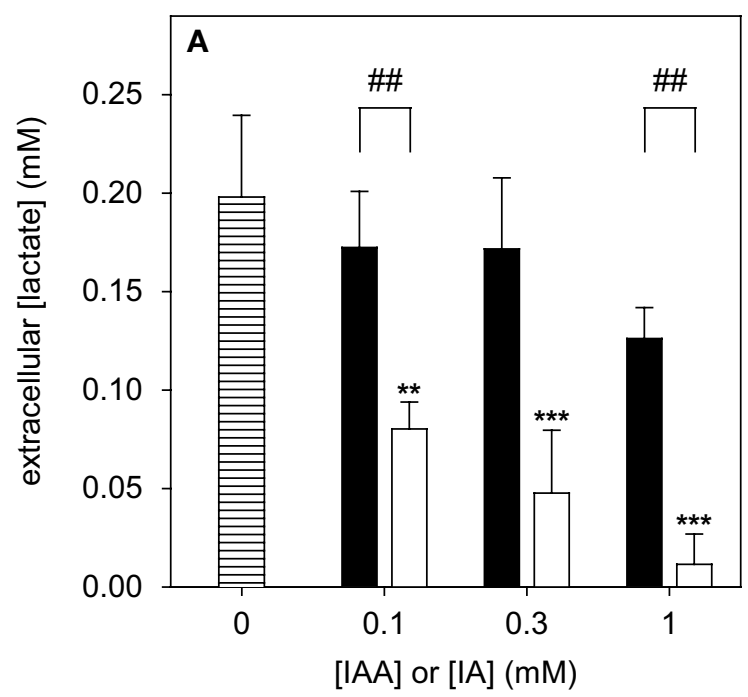

FIGURE 7 | Consequences of a treatment of cultured astrocytes with IAA or IA on the extracellular lactate concentration $(A)$ and on the specific cellular GAPDH activity (B). The cells were incubated for $60 \mathrm{~min}$ with IAA or IA in concentrations of up to $1 \mathrm{mM}$. The results represent mean \pm SD of data that were obtained on three $(\mathbf{A})$ or six $(\mathbf{B})$ independently prepared cultures that contained $80 \pm 8 \mu \mathrm{g}$ total protein per well

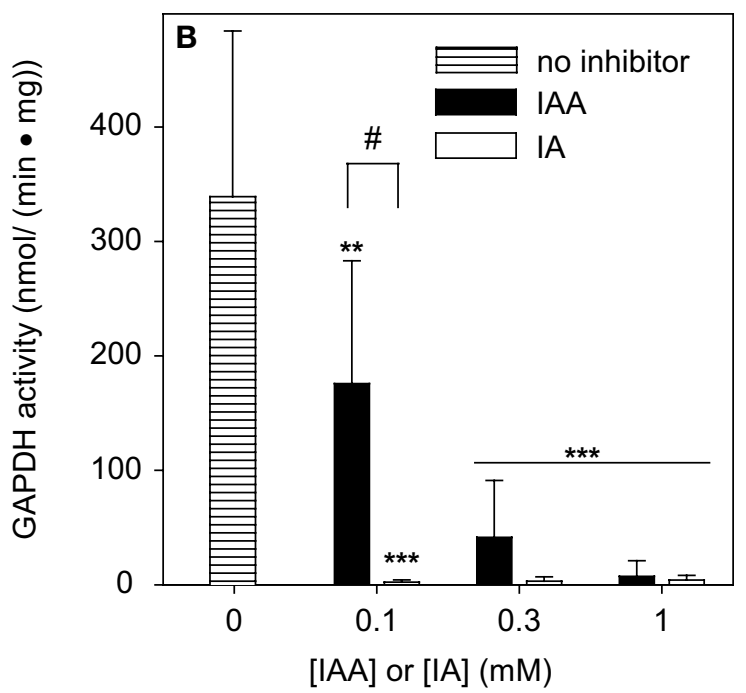

(A) or $37 \pm 11 \mu \mathrm{g}$ cytosolic protein per well (B). The significance of differences to the data obtained for the control condition (absence of inhibitor) are indicated by ${ }^{* *} p<0.01$ or ${ }^{* * *} p<0.001$. The significance of differences between the data observed after treatment with identical concentrations of IAA and IA was calculated by the paired $t$-test and is indicated by ${ }^{\#} p<0.05$ or $\# p<0.01$. high concentration of IAA or IA completely inactivated GAPDH (Figure 8; Table 2), they had no significant effect on the specific activities of G6PDH or LDH. However, $60 \mathrm{~min}$ incubation of cultured astrocytes with $1 \mathrm{mM}$ of IAA significantly lowered the specific activity of GR to $45 \%$ of controls (Table 2), whereas treatment of astrocytes with $1 \mathrm{mM}$ of IA caused only some decline 


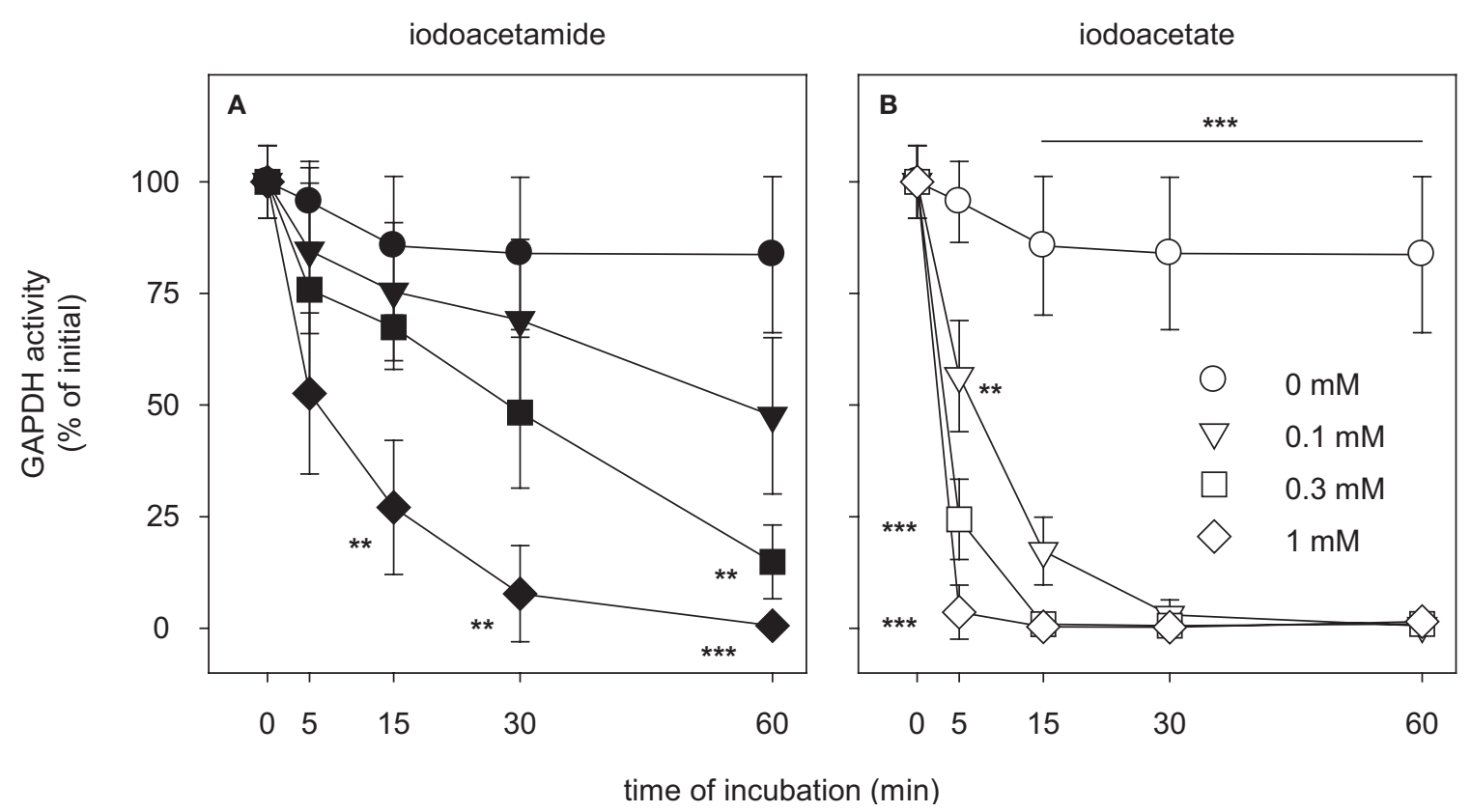

FIGURE 8 |Time dependency of the inhibition of GAPDH by IAA or IA in cultured astrocytes. The cells were incubated for up to $60 \mathrm{~min}$ without (circles) or with IAA (A) or IA (B) in concentrations of $0.1 \mathrm{mM}$ (triangles), $0.3 \mathrm{mM}$ (squares) or $1 \mathrm{mM}$ (diamonds). The results represent mean \pm SD of data that were obtained on three independently prepared cultures that contained $45 \pm 5 \mu \mathrm{g}$ cytosolic protein per well. The initial specific GAPDH activity (100\%) corresponded to $492 \pm 45 \mathrm{nmol} /(\mathrm{min} \times \mathrm{mg})$ cytosolic protein. The significance of differences to the data obtained for the control condition (absence of inhibitor) are indicated by ${ }^{*} p<0.01$ or ${ }^{* * *} p<0.001$.
Table 2 | Specific activities of enzymes in cultured astrocytes after exposure to IAA or IA.

\begin{tabular}{llcl}
\hline Enzyme & Inhibitor & Enzyme activity $(\mathbf{n m o l} / \mathbf{( m i n} \times \mathbf{m g}))$ & $\boldsymbol{n}$ \\
\hline \multirow{2}{*}{ GAPDH } & None & $339 \pm 145$ & 6 \\
& IAA & $8 \pm 13^{* * *}$ & 6 \\
& IA & $4 \pm 4^{* * *}$ & 6 \\
G6PDH & None & $108 \pm 12$ & 3 \\
& IAA & $96 \pm 8$ & 3 \\
& IA & $104 \pm 10$ & 3 \\
GR & None & $56 \pm 3$ & 3 \\
& IAA & $25 \pm 12^{*}$ & 3 \\
& IA & $40 \pm 6$ & 3 \\
LDH & None & $3278 \pm 374$ & 3 \\
& IAA & $3798 \pm 379$ & 3 \\
& IA & $3832 \pm 331$ &
\end{tabular}

Primary astrocyte cultures were incubated in the absence or the presence of $1 \mathrm{mM}$ of IAA or IA. After 60 min incubation, the cells were lysed and the specific activities of the enzymes glyceraldehyde-3-phosphate dehydrogenase (GAPDH), glucose-6-phosphate dehydrogenase (G6PDH), lactate dehydrogenase (LDH) and glutathione reductase (GR) were determined. The results represent mean $\pm S D$ of data that were obtained on $n$ independently prepared cultures that contained $45 \pm 5 \mu \mathrm{g}(n=3)$ or $37 \pm 11 \mu \mathrm{g}(n=6)$ cytosolic protein per well. The significance of differences to the data obtained for the control condition (none) is indicated by ${ }^{*} p<0.05$ or ${ }^{* *} p<0.001$.

in GR activity that did not reach the level of significance for the conditions investigated (Table 2).

\section{DISCUSSION}

The thiol reagents IAA and IA have frequently been used to inhibit astrocytic glycolysis (Bakken et al., 1998; Bickler and Kelleher, 1992; Gemba et al., 1994; Loreck et al., 1987; Ogata et al., 1995), but no information has been reported whether such treatments also affect the cellular GSH metabolism of astrocytes. To test for the consequences of a treatment of cultured astrocytes with IAA or IA on the GSH metabolism, the cells were exposed to various concentrations of the thiol reagents for up to $120 \mathrm{~min}$. During the first 60 min incubation with IAA or IA in concentrations of up to $1 \mathrm{mM}$ the cells remained viable as indicated by the lack of extracellular LDH activity, although glycolysis was inhibited and the cells were deprived of GSH. This lack of acute toxicity of such thiol reagents on cultured astrocytes confirms literature data (Gemba et al., 1994; Kahlert and Reiser, 2004; Nodin et al., 2005).

Comparison of the potential of IAA and IA to deprive cells of GSH and to inhibit glycolysis revealed substantial differences that have to our knowledge not been described so far. IAA was highly efficient to deprive the cells of GSH, whereas IA quickly inactivated GAPDH activity and slowed glycolysis. These differential effects are best demonstrated by the concentrations of the thiol reagents that had to be applied to obtain half-maximal effects for IAA and IA on GSH deprivation and lactate production which differed in both cases by one order of magnitude.

The GSH content of cultured astrocytes was lowered after exposure to IAA or IA. Such a decline of cellular non protein thiols has also been described for the kidney proximal tubule cell line LLC-PK1 after treatment with IAA (Chen and Stevens, 1991; Liu 
et al., 1996). The deprivation of cellular GSH after exposure to IAA or IA is most likely the direct consequence of the alkylation of GSH in viable cells, since both IAA and IA reacted also efficiently with GSH in a cell-free system in a time- and concentration-dependent manner. Loss of cellular GSx that is caused by damage of the cell membrane after exposure to IAA or IA or by an elevated export of GSH or GSSG from cultured astrocytes (Hirrlinger et al., 2001, 2002; Minich et al., 2006) can be excluded for the conditions used here, since an increased extracellular accumulation of GSx or GSSG was not observed.

The cellular GSH concentration of cultured astrocytes was quicker deprived by exposure to IAA than by treatment with IA. This difference is likely to reflect different chemical reactivity of IAA and IA with GSH, since IAA was also in cell-independent experiments more potent than IA to react with GSH. The reaction of a thiol with IAA or IA is initiated by a nucleophilic attack of the sulfhydryl group to the $\alpha$-carbon of IAA or IA. Since the $\alpha$-carbon of IA is less positive than that of IAA due to the neighboring negative carboxylate in IA compared to the uncharged carboxyamido group in IAA, IA will alkylate the thiol group of GSH less efficiently than IAA. Also differences in cellular uptake of IAA and IA could contribute at least in part to the observed differences in the potential of IAA and IA to deprive cultured astrocytes of their GSH. Different mechanisms of uptake of the uncharged IAA and the negatively charged IA could result in a higher cellular concentration of IAA, thereby further accelerating the chemical reaction of cellular GSH with IAA. However, the quick inhibition of GAPDH that was observed after exposure of cultured astrocytes to IA clearly demonstrates that the charged IA does enter the cells and that cellular IA concentrations are quickly reached that are sufficient to efficiently inhibit GAPDH.

Despite of its stronger reactivity toward GSH, IAA appears to be a less potent inhibitor of astrocytic glycolysis than IA. Already low concentrations of IA were highly efficient to inactivate GAPDH and to prevent lactate production by cultured astrocytes. Different rates of transport of IAA and IA can be excluded as explanation of this observation, since IA was also much more potent than IAA to inactivate GAPDH in cell lysates and since the quick deprivation of cellular GSH clearly demonstrates that IAA is efficiently taken up by the cells.

Reasons for this difference of IA and IAA to inactivate GAPDH could be that the active center of the enzyme binds the negatively charged IA better than the neutral IAA and/or that for sterical reasons IA fits better than IAA into the active side of GAPDH in an orientation that facilitates the alkylation of the thiol group in the active center. Alternatively, the alkylation of the astrocytic GAPDH by IAA and IA could be inversely modulated by the GAPDH cosubstrate $\mathrm{NAD}^{+}$. At least for yeast GAPDH was reported that the presence of $\mathrm{NAD}^{+}$supports alkylation by IA but inhibits alkylation by IAA (Byers and Koshland Jr., 1975). Such a behavior would explain the different potential of IAA and IA to inhibit GAPDH in astrocytic lysates, since the $\mathrm{NAD}^{+}$concentration in the GAPDH activity assay used was $2 \mathrm{mM}$, a concentration that has been reported to support alkylation of yeast GAPDH by IA and to suppress alkylation by IAA (Byers and Koshland Jr., 1975). With a specific $\mathrm{NAD}^{+}$content of about $1.5 \mathrm{nmol} / \mathrm{mg}$ protein $(\mathrm{X}$. Chen and R. Dringen, unpublished results) and a cytosolic volume of $4.1 \mu \mathrm{L} / \mathrm{mg}$ protein (Dringen and Hamprecht, 1998), the cytosolic $\mathrm{NAD}^{+}$concentration of cultured astrocytes is about $0.4 \mathrm{mM}$. This concentration of $\mathrm{NAD}^{+}$may already be sufficient to support alkylation of GAPDH from IA in living astrocytes, whereas the alkylation from IAA is slowed down.

Regarding the inhibition of enzymes in viable astrocytes, IAA and IA appear to be remarkable specific for GAPDH. The highly reactive thiol group in the active center of GAPDH appears to be an excellent target to become alkylated by these thiol reagents. In contrast, other dehydrogenases such as G6PDH or LDH were not inactivated by exposure of astrocytes to $1 \mathrm{mM}$ of IAA or IA. Only the cellular GR activity was partly inactivated by IAA. This slow but significant inactivation of GR confirms literature data that demonstrate that at least purified GR is sensitive to inactivation by IAA (Arscott et al., 1981; Pai and Schulz, 1983; Untucht-Grau et al., 1981). Thus, the quick depletion of cellular GSH appears to be the strongest side effect of a treatment of cultured astrocytes with $1 \mathrm{mM}$ of IAA or IA.

Incubation of cultured astrocytes with IAA or IA caused severe cell death after incubation of the cells for more than $60 \mathrm{~min}$ with the thiol reagents. Both the inhibition of glycolysis and the decline in cellular GSH could contribute to the observed toxicity of IAA and IA after longer exposure to astrocytes. Since cultured astrocytes are able to survive depletion of their cellular GSH for several hours (Waak and Dringen, 2006), the cellular GSH deprivation appear not to be the primary cause of the delayed cell death observed after treatment with the thiol reagents. It is more likely that the depletion of cellular ATP that has been reported for cultured brain cells at least for the treatment with IA (Hernandez-Fonseca et al., 2008; Nodin et al., 2005; Ogata et al., 1995) is responsible for the observed cell death after exposure to IAA or IA.

IAA and IA are frequently used to slow glycolysis by inhibiting the GAPDH in cultured astrocytes. For such studies millimolar concentrations of IAA or IA have been used for incubation periods above $5 \mathrm{~min}$ [ $10 \mathrm{mM}$ IAA for $2.5 \mathrm{~h}$ (Loreck et al., 1987), $3.5 \mathrm{mM}$ IA for $15 \mathrm{~min}$ (Bickler and Kelleher, 1992), $1 \mathrm{mM}$ IA for $30 \mathrm{~min}$ (Gemba et al., 1994), 5 mM IA for 30 min (Ogata et al., 1995)]. In our hands, such conditions deprive cultured astrocytes quickly of GSH. Thus, a contribution of a compromised cellular GSH metabolism to the reported effects observed after treatment of cultured astrocytes with millimolar concentrations of IAA or IA has to be considered. Since IAA lowers quickly the cellular GSH content of cultured astrocytes, we recommend not to use this compound for inactivation of GAPDH and glycolysis. In contrast to IAA, IA lead to a quick inactivation of GAPDH activity and slows down lactate production, without affecting the cellular GSH content substantially. Therefore, we suggest to use a low concentration of IA $(0.1 \mathrm{mM})$ for $30 \mathrm{~min}$ or a high concentration of IA $(1 \mathrm{mM})$ for $5 \mathrm{~min}$ to inhibit glycolysis in cultured astrocytes, since these conditions do not substantially compromise the GSH metabolism of the cells. 


\section{REFERENCES}

Adachi, Y., Chen, W., Shang, W. H., and Kamata, T. (2005). Development of a direct and sensitive detection method for DNA-binding proteins based on electrophoretic mobility shift assay and iodoacetamide derivative labeling. Anal. Biochem. 342, 348-351.

Albrecht, J., Talbot, M., Kimelberg, H. K., and Aschner, M. (1993). The role of sulfhydryl groups and calcium in the mercuric chloride-induced inhibition of glutamate uptake in rat primary astrocyte cultures. Brain Res. 607, 249-254.

Aoyama, K., Watabe, M., and Nakaki, T. (2008). Regulation of neuronal glutathione synthesis. J. Pharmacol. Sci. 108, 227-238.

Arscott, L. D., Thorpe, C., and Williams, C. H. Jr. (1981). Glutathione reductase from yeast. Differential reactivity of the nascent thiols in two-electron reduced enzyme and properties of a monoalkylated derivative. Biochemistry 20, 1513-1520.

Aschner, M., Mullaney, K. J., Fehm, M. N., Vitarella, D., Wagoner, D. E. Jr., and Kimelberg, H. K. (1994). The role of sulfhydryl groups in D-aspartate and rubidium release from neonatal rat primary astrocyte cultures. Brain Res. 648, 16-23.

Bakken, I. J., White, L. R., Unsgard, G., Aasly, J., and Sonnewald, U. (1998). $\left[\mathrm{U}-{ }^{13} \mathrm{C}\right]$ glutamate metabolism in astrocytes during hypoglycemia and hypoxia. J. Neurosci. Res. 51, 636-645.

Ballatori, N., Krance, S. M., Marchan, R., and Hammond, C. L. (2008). Plasma membrane glutathione transporters and their roles in cell physiology and pathophysiology. Mol. Aspects Med. (in press).

Bi, J., Jiang, B., Liu, J. H., Lei, C., Zhang, X. L., and An, L. J. (2008). Protective effects of catalpol against $\mathrm{H}_{2} \mathrm{O}_{2}$-induced oxidative stress in astrocytes primary cultures. Neurosci. Lett. 442, 224-227.

Bickler, P. E., and Kelleher, J. A. (1992). Fructose-1,6-bisphosphate stabilizes brain intracellular calcium during hypoxia in rats. Stroke 23 , 1617-1622.

Bishop, G. M., Dringen, R., and Robinson, S. R. (2007). Zinc stimulates the production of toxic reactive oxygen species (ROS) and inhibits glutathione reductase in astrocytes. Free Radic. Biol. Med. 42, 1222-1230.

Bisswanger, H. (2004). Practical Enzymology. Weinheim, WILEY-VCH Verlag.

Byers, L. D., and Koshland, D. E. Jr. (1975). The specificity of induced conformational changes. The case of yeast glyceraldehyde-3-phosphate dehydrogenase. Biochemistry 14, 3661-3669.

Chen, Q., and Stevens, J. L. (1991). Inhibition of iodoacetamide and t-butylhydroperoxide toxicity in LLC-PK1 cells by antioxidants: a role for lipid peroxidation in alkylation induced cytotoxicity. Arch. Biochem. Biophys. 284, 422-430.

Cooper, A. J., and Kristal, B. S. (1997). Multiple roles of glutathione in the central nervous system. Biol. Chem. 378, 793-802.

Deutsch, J. (1984). Glucose-6-phosphate dehydrogenase. In Methods of Enzymatic Analysis,H.U. Bergmeyer, J. Bergmeyer and M. Graßl, eds (Weinheim, Verlag Chemie), pp. 190-197.

Dringen, R. (2000). Metabolism and functions of glutathione in brain. Prog. Neurobiol. 62, 649-671.

Dringen, R. (2009). Neuron-glia coupling in glutathione metabolism. In The New Encyclopedia of Neuroscience, L. Squire, T. Albright, F. Bloom, F. Gage and N. Spitzer, eds (Oxford, Elsevier), pp. 733-737.

Dringen, R., Gebhardt, R., and Hamprecht, B. (1993). Glycogen in astrocytes - possible function as lactate supply for neighboring cells. Brain Res. 623, 208-214.

Dringen, R., and Hamprecht, B. (1996), Glutathione content as an indicator for the presence of metabolic pathways of amino acids in astroglial cultures. $J$. Neurochem. 67, 1375-1382.

Dringen, R., and Hamprecht, B. (1998). Glutathione restoration as indicator for cellular metabolism of astroglial cells. Dev. Neurosci. 20, 401-407.

Dringen, R., Kranich, O., and Hamprecht, B. (1997). The $\gamma$-glutamyl transpeptidase inhibitor acivicin preserves glutathione released by astroglial cells in culture. Neurochem. Res. $22,727-733$.

Dringen, R., Kussmaul, L., and Hamprecht, B. (1998). Detoxification of exogenous hydrogen peroxide and organic hydroperoxides by cultured astroglial cells assessed by microtiter plate assay. Brain Res. Protc. 2 , 223-228.

Dringen, R., Pawlowski, P. G., and Hirrlinger, J. (2005). Peroxide detoxification by brain cells. J. Neurosci. Res. $79,157-165$.

Gali, R. R., and Board, P. G. (1997). Identification of an essential cysteine residue in human glutathione synthase. Biochem. J. 321, 207-210.

Gegg, M. E., Beltran, B., Salas-Pino, S., Bolanos, J.P., Clark, J. B., Moncada, S. and Heales, S. J. (2003). Differential effect of nitric oxide on glutathione metabolism and mitochondrial function in astrocytes and neurones: implications for neuroprotection/ neurodegeneration? J. Neurochem $86,228-237$.

Gegg, M. E., Clark, J., and Heales, S. J. (2005). Co-culture of neurones with glutathione deficient astrocytes leads to increased neuronal susceptibility to nitric oxide and increased glutamate-cysteine ligase activity. Brain Res. 1036, 1-6.

Gemba, T., Oshima, T., and Ninomiya, M (1994). Glutamate efflux via the reversal of the sodium-dependent glutamate transporter caused by glycolytic inhibition in rat cultured astrocytes. Neuroscience 63, 789-795.

Giordano, G., Kavanagh, T. J., and Costa, L. G. (2008). Neurotoxicity of a polybrominated diphenyl ether mixture (DE-71) in mouse neurons and astrocytes is modulated by intracellular glutathione levels. Toxicol. Appl. Pharmacol. 232, 161-168.

Gutterer, J. M., Dringen, R., Hirrlinger, J., and Hamprecht, B. (1999). Purification of glutathione reductase from bovine brain, generation of an antiserum, and immunocytochemical localization of the enzyme in neural cells J. Neurochem. 73, 1422-1430.

Hamprecht, B., and Löffler, F. (1985). Primary glial cultures as a model for studying hormone action. Methods Enzymol. 109, 341-345.

Hayes, J. D., Flanagan, J. U., and Jowsey, I. R. (2005). Glutathione transferases. Annu. Rev. Pharmacol. Toxicol. 45, 51-88.

Hernandez-Fonseca, K., CardenasRodriguez, N., Pedraza-Chaverri, J. and Massieu, L. (2008). Calciumdependent production of reactive oxygen species is involved in neuronal damage induced during glycolysis inhibition in cultured hippocampal neurons. J. Neurosci. Res. 86 , 1768-1780.

Hirrlinger, J., Konig, J., Keppler, D. Lindenau, J., Schulz, J. B., and Dringen, R. (2001). The multidrug resistance protein MRP1 mediates the release of glutathione disulfide from rat astrocytes during oxidative stress. J. Neurochem. 76, 627-636.

Hirrlinger, J., Schulz, J. B., and Dringen, R. (2002). Glutathione release from cultured brain cells: multidrug resistance protein 1 mediates the release of GSH from rat astroglial cells. J. Neurosci. Res. 69, 318-326.

Kahlert, S., and Reiser, G. (2004). Glial perspectives of metabolic states during cerebral hypoxia - calcium regulation and metabolic energy. Cell Calcium 36 , 295-302.

Kauppinen, R. A., Enkvist, K., Holopainen, I., and Akerman, K. E.
(1988). Glucose deprivation depolarizes plasma membrane of cultured astrocytes and collapses transmembrane potassium and glutamate gradients. Neuroscience 26, 283-289.

Kubatova, A., Murphy, T. C., Combs, C., and Picklo, M. J. Sr. (2006). Astrocytic biotransformation of trans-4-hydroxy 2-nonenal is dosedependent. Chem. Res. Toxicol. 19, 844-851.

Liddell, J. R., Dringen, R., Crack, P. J., and Robinson, S. R. (2006a). Glutathione peroxidase 1 and a high cellular glutathione concentration are essential for effective organic hydroperoxide detoxification in astrocytes. Glia 54 873-879.

Liddell, J. R., Hoepken, H. H., Crack, P. J., Robinson, S. R., and Dringen, R. (2006b). Glutathione peroxidase 1 and glutathione are required to protect mouse astrocytes from iron-mediated hydrogen peroxide toxicity.J. Neurosci. Res. 84, 578-586.

Liu, H., Lightfoot, R., and Stevens, J. L. (1996). Activation of heat shock factor by alkylating agents is triggered by glutathione depletion and oxidation of protein thiols. J. Biol. Chem. 271, 4805-4812.

Loreck, D. J., Galarraga, J., Van der Feen, J., Phang, J. M., Smith, B. H., and Cummins, C.J.(1987). Regulation of the pentose phosphate pathway in human astrocytes and gliomas. Metab. Brain Dis. 2, 31-46.

Lowry, O. H., Rosebrough, N. J., Farr, A. L. and Randall, R. (1951). Protein measurement with the Folin phenol reagent. J. Biol. Chem. 193, 265-275.

Margis, R., Dunand, C., Teixeira, F. K. and Margis-Pinheiro, M. (2008). Glutathione peroxidase family - an evolutionary overview. FEBS J. 275, 3959-3970.

Minich, T., Riemer, J., Schulz, J.B. Wielinga, P., Wijnholds, J., and Dringen, R. (2006). The multidrug resistance protein 1 (Mrp1), but not Mrp5, mediates export of glutathione and glutathione disulfide from brain astrocytes. J. Neurochem. 97 , 373-384.

Nodin, C., Nilsson, M., and Blomstrand, F. (2005). Gap junction blockage limits intercellular spreading of astrocytic apoptosis induced by metabolic depression. J. Neurochem. 94 1111-1123.

Ogata, T., Nakamura, Y., Tsuji, K., Shibata, T., and Kataoka, K. (1995). A possible mechanism for the hypoxia-hypoglycemia-induced release of excitatory amino acids from cultured hippocampal astrocytes. Neurochem. Res. 20, 737-743. 
Pai, E. F., and Schulz, G. E. (1983). The catalytic mechanism of glutathione reductase as derived from $\mathrm{x}$-ray diffraction analyses of reaction intermediates. J. Biol. Chem. 258, 1752-1757.

Parkinson, F. E., Sinclair, C. J., Othman, T., Haughey, N. J., and Geiger, J.D. (2002). Differences between rat primary cortical neurons and astrocytes in purine release evoked by ischemic conditions. Neuropharmacology 43, 836-846.

Sabri, M.I., and Ochs, S. (1971). Inhibition of glyceraldehyde-3-phosphate dehydrogenase in mammalian nerve by iodoacetic acid. J. Neurochem. 18, 1509-1514.

Sagara, J.-I., and Sugita, Y. (2001). Characterization of cytosolic glutathione $S$-transferase in cultured astrocytes. Brain Res. 902, 190-197.

Sun, F. F., Fleming, W. E., and Taylor, B. M. (1993). Degradation of membrane phospholipids in the cultured human astroglial cell line UC-11MG during
ATP depletion. Biochem. Pharmacol. 45, 1149-1155.

Sun, M. C., Chen, C. D., Huang, Y. S., Wu, Z. S., and Ho, Y. P. (2008). Matrixassistedlaserdesorption/ionization-MSbased relative quantification of peptides and proteins using iodoacetamide and $\mathrm{N}$-methyliodoacetamide as labeling reagents. J. Sep. Sci. 31, 538-547.

Taylor, B. M., Fleming, W. E., Benjamin, C. W., Wu, Y., Mathews, W. R., and Sun, F. F. (1996). The mechanism of cytoprotective action of lazaroids I: Inhibition of reactive oxygen species formation and lethal cell injury during periods of energy depletion. J. Pharmacol. Exp. Ther. 276, 1224-1231.

Tietze, F. (1969). Enzymatic method for quantitative determination of nanogram amounts of total oxidized glutathione: applications to mammalian blood and other tissues. Anal. Biochem. 27, 502-522.
Untucht-Grau, R., Schirmer, R. H. Schirmer, I., and Krauth-Siegel, R. L. (1981). Glutathione reductase from human erythrocytes: amino-acid sequence of the structurally known FAD-binding domain. Eur. J. Biochem. 120, 407-419.

Waak, J., and Dringen, R. (2006). Formation and rapid export of the monochlorobimane-glutathione conjugate in cultured rat astrocytes. Neurochem. Res. 31, 1409-1416.

Williams, D. K. Jr., Meadows, C. W. Bori, I. D., Hawkridge, A. M. Comins, D. L., and Muddiman, D. C. (2008).Synthesis, characterization, and application of iodoacetamide derivatives utilized for the ALiPHAT strategy. J. Am. Chem. Soc. 130, 2122-2123.

Williamson, J. R. (1967). Glycolytic control mechanisms. 3. Effects of iodoacetamide and fluoroacetate on glucose metabolism in the perfused rat heart. J. Biol. Chem. 242, 4476-4485.
Conflict of Interest Statement: The authors declare that the research was conducted in the absence of any commercial or financial relationships that could be construed as a potential conflict of interest.

Received: 13 December 2008; paperpending published: 07 January 2009; accepted: 12 March 2009; published online: 24 March 2009

Citation: Schmidt MM and Dringen $R$ (2009) Differential effects of iodoacetamide and iodoacetate on glycolysis and glutathione metabolism of cultured astrocytes. Front. Neuroenerg. (2009) 1:1. doi: 10.3389/neuro.14.001.2009

Copyright (C) 2009 Schmidt and Dringen. This is an open-access article subject to an exclusive license agreement between the authors and the Frontiers Research Foundation, which permits unrestricted use, distribution and reproduction in any medium, provided the original authors and source are credited. 